\title{
Martorell's Ulcer: Diagnostic and Therapeutic Challenge
}

\author{
Ana Paula Frade Lima Pinto ${ }^{a}$ Nelson Araújo Silva Jr. ${ }^{b}$ \\ Carolina Teixeira Osorio ${ }^{c}$ Lina Maria Rivera ${ }^{b}$ Sueli Carneiro $^{a, d}$ \\ Marcia Ramos-e-Silva ${ }^{a} \quad$ Blanca Elena Rios Gomes Bica ${ }^{b}$ \\ ${ }^{a}$ Sector of Dermatology and Post-Graduation Course, University Hospital and \\ School of Medicine, Federal University of Rio de Janeiro, 'bector of Rheumatology \\ and Post-Graduation Course, University Hospital and School of Medicine, Federal \\ University of Rio de Janeiro, 'Sector of Medical Clinics, Lourenço Jorge Municipal \\ Hospital, and ${ }^{\mathrm{d}}$ Sector of Dermatology, University Hospital and School of Medicine, \\ University of the State of Rio de Janeiro, Rio de Janeiro, Brazil
}

\section{Key Words}

Martorell's ulcer · Hypertensive ulcer · Hypertension · Ischemia

\begin{abstract}
Martorell's ulcer is an uncommon ischemic and extremely painful lesion located in the distal portion of the lower limb, resulting from severe systemic and poorly controlled hypertension. It is common in women between 50 and 70 years of age. The diagnosis is clinical and mostly belated, following exclusion of other causes. The response to treatment takes time and is unsatisfactory. A combination of several drugs associated with surgery may be required for wound healing. The authors present a case of Martorell's hypertensive ulcer, with emphasis on the diagnostic and therapeutic difficulties.

(C) 2015 S. Karger AG, Basel
\end{abstract}

\section{Introduction}

The most common causes of ulcers in the lower limbs are arterial insufficiency and venous stasis [1]. Martorell's hypertensive ulcer is an ischemic lesion of the tissue caused by obstruction of the small arterioles of the medial artery.

Haxthausen [2], in 1940, for the first time reported the association of ischemic ulcers as a consequence of arterial hypertension complications, and Martorell, five years later, published four cases correlating systemic arterial hypertension, arteriolar lesion and ulcer for-

\section{KARGER 125\% Prot. Marcici Ramose-esiva \\ Rua Dona Mariana $143 / \mathrm{C}-32$ \\ Botafogo, Rio de Janeiro 22280-020 (Brazil) \\ E-Mail ramos.e.silva@dermato.med.br}


Pinto et al.: Martorell's Ulcer: Diagnostic and Therapeutic Challenge

mation $[3,4]$. These findings were supported by Hines and Farber from the Mayo Clinic [5]. The clinical criteria described by Martorell for the diagnosis of hypertensive ulcer were: location on the inner side of the distal third of the lower limbs; diastolic arterial hypertension in the lower limbs; 'hyperpulsatility' of the arteries of the lower limbs, absence of arterial calcifications; absence of chronic venous insufficiency; symmetrical lesions or residual hyperpigmentation of previous ulceration in the inner side of the inferior limb; increased pain in the horizontal position, with greater prevalence in women $[3,4,6]$.

It is believed that the pathogenesis of hypertensive ulcer is related to local factors of the microvasculature and not to involvement of large vessels, as observed in the most common peripheral vascular diseases. Trauma can be a triggering factor, although half of the ulcers arise spontaneously [7]. From the pathophysiological point of view, the dermal arterioles with uncontrolled systemic arterial hypertension present arteriosclerotic changes, such as hyperplasia of the core elements of the middle layer cells in the vessels with thickening of the elastic lamina. Such a process, called hyalinosis [7-9], leads to an increase in the dermal arterioles lumen diameter $[6,10]$. Luminal stenosis produces increased local vascular resistance and reduced skin perfusion pressure [11].

Hypertensive ulcers are more common in women between 50 and 70 years of age, often symmetrical and located in the distal inner side of the lower limbs. Pain in greater intensity than in ulcers of other etiologies, referred to as being disproportionate to the size of the lesion, is the most relevant symptom. Inefficiency of ordinary analgesics is common $[1,12]$. Classically, the ulcer has variable depth, necrotic base and violaceous edges. The presence of satellite lesions and irregular edges are also features that suggest additional cutaneous ischemia. The diagnosis is usually belated and requires the exclusion of other causes. The healing process is slow and the response to treatment is poor [13].

Proposed treatments are antihypertensive therapy, especially with drugs that reduce vasoconstriction, such as calcium channel blockers and inhibitors of angiotensin-converting enzyme. Pacifico et al. [14] in 2011 suggested the use of prostaglandin E $\left(\mathrm{PGE}_{1}\right)$.

\section{Case Report}

A black woman, a 40-year-old housewife born in Rio de Janeiro, was referred for ulcers on the toes for 2 months. She reported intense pain in the lesions with a progressive increase in size. At the primary care clinic, she was treated with benzathine, penicillin and ciprofloxacin in addition to local care, however without presenting significant improvement. She had systemic arterial hypertension upon irregular monitoring, without adequate blood pressure control. She was taking digoxin $0.25 \mathrm{mg} /$ day, carvedilol $3.125 \mathrm{mg} /$ day, captopril $100 \mathrm{mg} /$ day, furosemide $80 \mathrm{mg} /$ day, spironolactone $50 \mathrm{mg} /$ day and simvastatin $20 \mathrm{mg} /$ day. Both parents had suffered from hypertension and had died from encephalic strokes.

At the initial physical examination, the patient did not present fever, but was hypertensive (blood pressure 240/120 mm Hg), with mild edema of the lower limbs. There were two irregular edge ulcers and necrotic bases in the lower limbs located in the 3rd and 4th right and left toes (fig. 1, fig. 2, fig. 3). She did not show any signs of inflammation or wound secretion in the region. Peripheral arterial pulses of the posterior tibial and posterior tibial arteries were palpable bilaterally. Radiography of the feet excluded osteomyelitis. Eye fundus examination showed Keith-Wagener-Baker hypertensive retinopathy grade III (arteriolar narrowing, with silver wire arteries, increased vascular tortuosity with A/V pathological groups). Transthoracic echocardiography demonstrated parietal concentric hypertrophy of the left ventricle with diastolic dysfunction grade I and left atrial enlargement. Doppler study 
Pinto et al.: Martorell's Ulcer: Diagnostic and Therapeutic Challenge

of the carotid and vertebral arteries only revealed mild bilateral intimal thickening without atheromatous plaques. In echo color Doppler of the lower limbs, arterial thickening and irregularities were detected without parietal diffuse atherosclerosis and with normal bilateral flow.

Histopathological examination of the biopsy of the ulcer in the left leg showed a nonspecific chronic inflammation process with ulceration, consistent with the diagnosis of Martorell's ulcer. The clinical picture and laboratory tests showed that the ulcers had a hypertensive etiology. The patient was admitted for a proper treatment for systemic arterial hypertension and surgical debridement of the ulcer (fig. 4). The local dressings were made with petrolatum and the ulcer progressed with healing.

\section{Discussion}

Martorell's hypertensive ulcer is an unusual injury and, although cases have been seen in men, it is more common in women. It is frequently symmetrical and located in the distal third and anterolateral surfaces of the lower limbs [15].

The most common histopathological findings are thickening of the elastic lamina, proliferation of the intimal layer and hyperplasia of the middle layer with hyalinization resulting in luminal narrowing [16]. Studies have shown that the presence of intimal hyperplasia is the primary event for ulcer formation. The shear stress, caused by persistently high blood pressure levels, stimulates endothelial remodeling with thickening of the wall vessel, luminal narrowing and consequent obstruction of the blood flow. It was also admitted that there is a loss of the offsetting vasodilation physiological reflex of the distal arterioles in the obstructed region, further compromising the tissue perfusion. When the perfusion reaches critical levels, cutaneous ischemia occurs, with epidermal necrosis and ulcer formation [11].

Total ulcer healing requires the combination of various therapies. Reduction of blood pressure levels is critical to the success of the treatment and not only prevents increased vascular damage, but improves blood supply through local vasodilation. Nonselective betablockers are contraindicated for reducing cardiac output, worsening the skin perfusion pressure. The drugs of choice are calcium channel blockers and angiotensin-converting enzyme inhibitors, and all patients must be anticoagulated with heparin or coumarin [17].

Surgical treatments involve the debridement of devitalized tissue with second intention closure or skin grafting and lumbar sympathectomy. Surgical closure of lesions $>4 \mathrm{~cm}^{2}$ is recommended [18]. Lumbar sympathectomy aims at promoting vasodilation, improving perfusion of the affected limb and controlling pain. The result is variable, from complete recovery to little impact on healing [19].

Mild to moderate pain can be managed by the use of ordinary painkillers such as nonsteroidal anti-inflammatories, and in severe cases opioids are the drugs of choice. The use of spinal cord stimulation therapy, with good results in reduction of pain and healing of ulcers, has been mentioned and consists of the use of small electrodes that stimulate certain points of the spinal cord, influencing the transmission of the pain signals to the brain [20].

The type of therapy called hyperbaric oxygen therapy consists in the supply of pure oxygen in a pressurized environment above atmospheric pressure. Its action mechanism is not entirely understood, but it can be used as an adjunct in the treatment of chronic wounds, although the level of evidence in patients with Martorell's ulcer is low [21].

Behavioral measures, such as avoiding trauma, stopping to smoke and wearing compressive stockings ( 25 and $30 \mathrm{~mm} \mathrm{Hg}$ ) must be encouraged [22]. 
Pinto et al.: Martorell's Ulcer: Diagnostic and Therapeutic Challenge

\section{Conclusion}

In the case presented, the patient featured four out of the seven criteria set up by Martorell. Complementary tests allowed the exclusion of other etiologies. The lower limbs Doppler excluded chronic venous insufficiency and coagulopathy, while the histopathological examination did not show any signs of cutaneous vasculitis. The observation of lesions secondary to hypertension in other target organs also contributed to the diagnostic conclusion. The patient underwent daily dressing while hospitalized. After the optimization of oral antihypertensive medication doses, obtaining acceptable pressure levels allowed the lesion to heal.

Hypertensive ulcer should always be considered in the differential diagnosis of painful lesions of the lower limbs.

\section{Statement of Ethics}

Our patient gave her written authorization for the publication of her case and the authors followed all ethical guidelines.

\section{Disclosure Statement}

The authors declare no conflict of interest.

\section{References}

1 Vuerstaek JD, Reeder SW, Henquet CJ, Neumann HA: Arteriolosclerotic ulcer of Martorell. J Eur Acad Dermatol Venereol 2010;24:867-874.

2 Haxthausen H: Arteriosclerotic ulcers of the leg. Nord Med 1940;8:1663-1665.

3 Martorell F: Las úlceras supramaleolares por arteriolitis de las grandes hipertensas. Acta Inst Policlin Barc 1945;1:6-9.

4 Martorell F: Hypertensive ulcer of the leg. Angiology 1950;1:133-140.

5 Hines EA Jr, Farber EM: Ulcer of the leg due to arteriolosclerosis and ischemia, occurring in the presence of hypertensive disease (hypertensive-ischemic ulcers). Proc Staff Meet Mayo Clin 1946;21:337-346.

6 Martorell F: Hypertensive ulcer of the leg. J Cardiovasc Surg (Torino) 1978;19:599-600.

7 Henderson CA, Highet AS, Lane AS, Hall R: Arterial hypertension causing leg ulcers. Clin Exp Dermatol 1995;20:107-114.

-8 Leu HJ: Hypertensive ischemic leg ulcer (Martorell's ulcer): a specific disease entity? Int Angiol 1992;11: 132-136.

9 Davison S, Lee E, Newton ED: Martorell's ulcer revisited. Wounds 2003;15:208-212.

10 Farber EM, Hines EA, Montgomery H, Craig WN: The arterioles of the skin in essential hypertension. J Invest Dermatol 1947;9:285-298.

11 Duncan HJ, Faris IB: Martorell's hypertensive ischemic leg ulcers are secondary to an increase in the local vascular resistance. J Vasc Surg 1985;2:581-584.

$\longrightarrow 12$ Schnier BR, Sheps SG, Juergens JL: Hypertensive ischemic ulcer. A review of 40 cases. Am J Cardiol 1966;17: 560-565.

13 Choucair MM, Fivenson DP: Leg ulcer diagnosis and management. Dermatol Clin 2001;19:659-678.

14 Pacifico F, Acernese CA, Di Giacomo A: PGE 1 therapy for Martorell's ulcer. Int Wound J 2011;8:140-144.

15 Graves JW, Morris JC, Sheps SG: Martorell's hypertensive leg ulcer: case report and concise review of the literature. J Hum Hypertens 2001;14:279-283.

-16 Wooling KR: Hypertensive-ischemic ulcer. An atypical ischemic necrosis of the skin. JAMA 1964;187: 196-201.

17 Hermida FL, Aramayo AR, Bertranou EG: Tratamiento ambulatorio de la úlcera arteriolar hipertensiva de Martorell. Rev Argent Cir 1996;71:65-67.

18 Villanueva JA, Vicente L, Mazzinari G, Fabregat GA, Monsalve JM: Use of a spinal cord stimulator for treatment of Martorell hypertensive ulcer. Reg Anesth Pain Med 2001;36:83-86. 


\section{Case Reports in Dermatology}

\begin{tabular}{l|l}
\hline \multicolumn{2}{l|}{ Case Rep Dermatol 2015;7:199-206 } \\
\hline DOI: $10.1159 / 000430884$ & $\begin{array}{l}\text { C } 2015 \text { S. Karger AG, Basel } \\
\text { www.karger.com/cde }\end{array}$ \\
\hline
\end{tabular}

Pinto et al.: Martorell's Ulcer: Diagnostic and Therapeutic Challenge

19 Palou J: Lumbar sympathectomy in the treatment of hypertensive ischemic ulcers of the leg (Martorell's syndrome). Circulation 1955;12:239-241.

20 Freire BM, Fernandes NC, Piñeiro-Maceira J: Úlcera hipertensiva de Martorell: relato de caso. An Bras Dermatol 2006;81:327-331.

21 Gill AL, Bell CN: Hyperbaric oxygen: its uses, mechanisms of action and outcomes. QJM 2004;97:385-395.

-22 Atiyeh BS, Ioannovich J, Al-Amm CA, El-Musa KA: Management of acute and chronic open wounds: the importance of moist environment in optimal wound healing. Curr Pharm Biotechnol 2002;3:179-195.

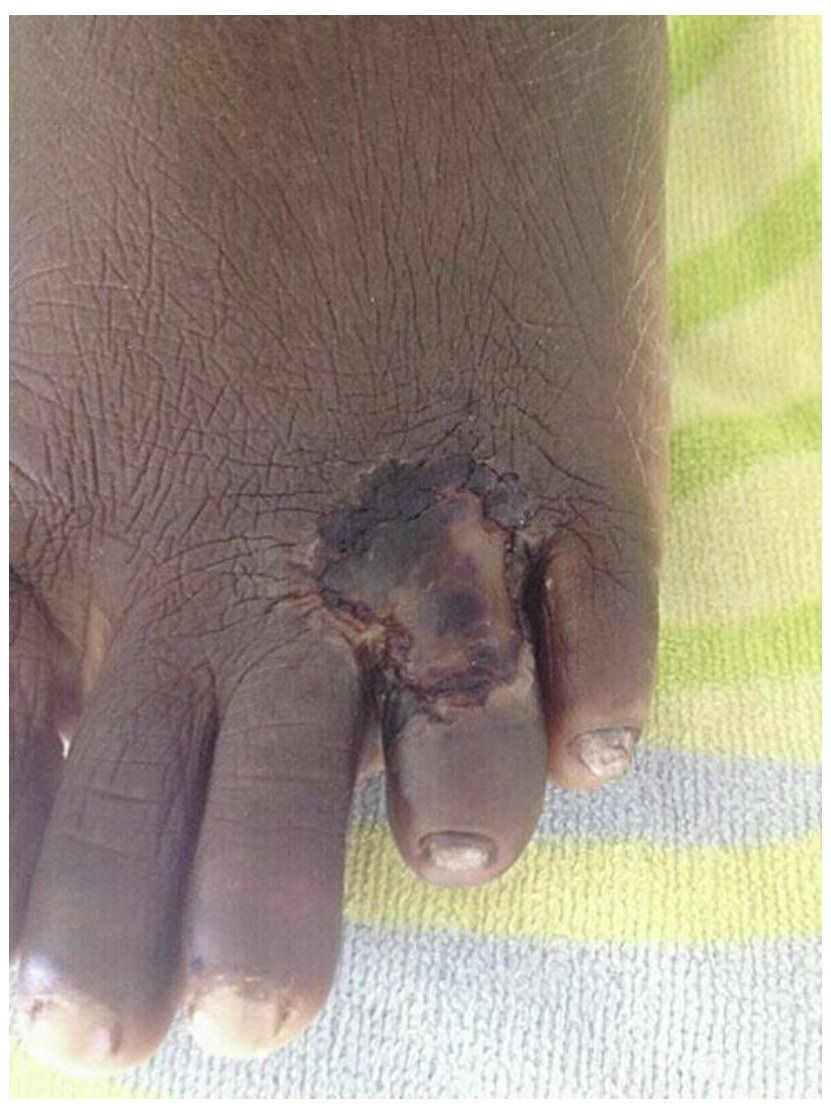

Fig. 1. Ulcer with irregular borders and dry necrosis at the base of the 4 th left toe. 
Pinto et al.: Martorell's Ulcer: Diagnostic and Therapeutic Challenge

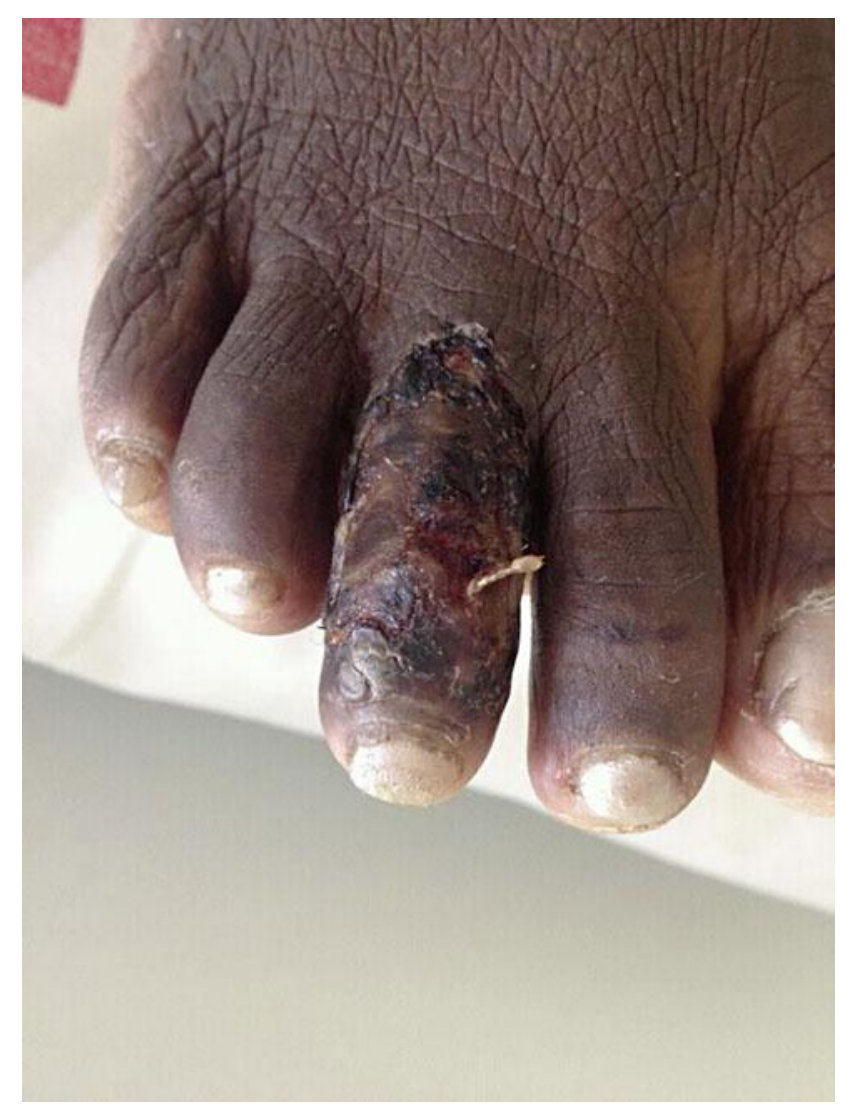

Fig. 2. Ulcer involving all of the 3rd right toe with dry necrosis. 
Case Reports in
Dermatology

Case Rep Dermatol 2015;7:199-206

DOI: $10.1159 / 000430884$

C 2015 S. Karger AG, Basel

www.karger.com/cde

Pinto et al.: Martorell's Ulcer: Diagnostic and Therapeutic Challenge

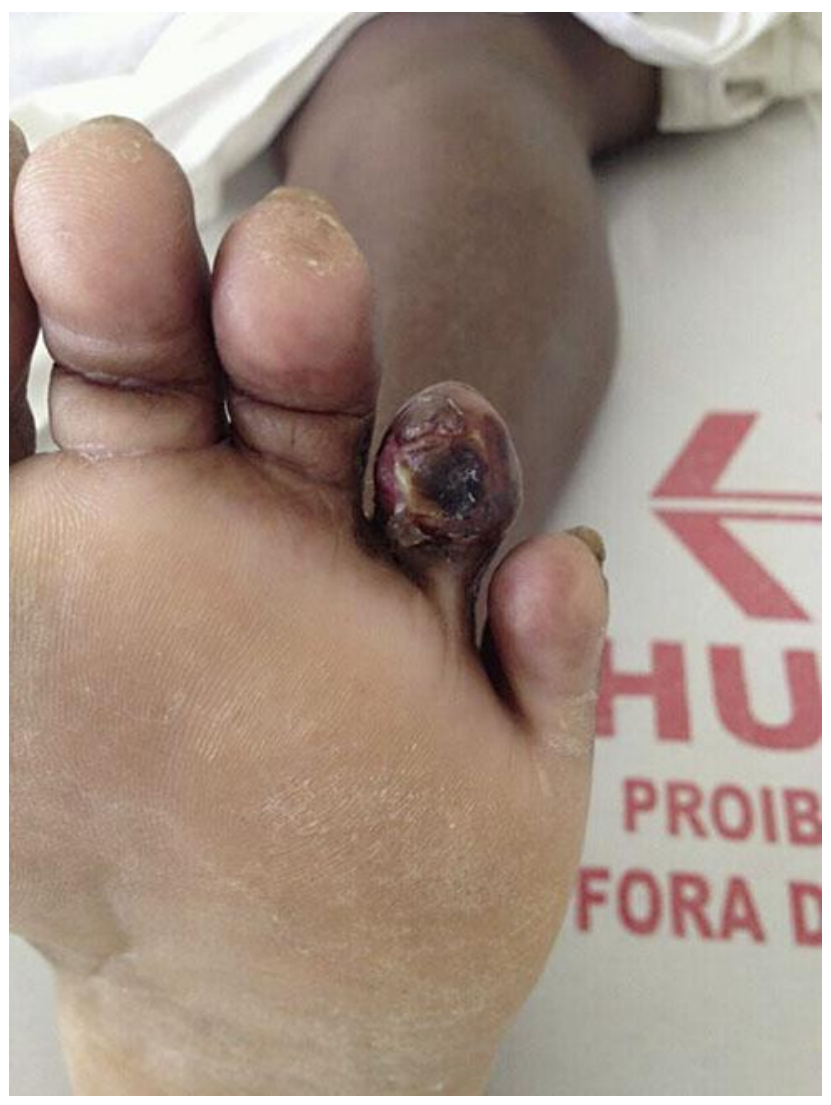

Fig. 3. Detail of the extension of the lesion. 


\section{Case Reports in Dermatology}

Pinto et al.: Martorell's Ulcer: Diagnostic and Therapeutic Challenge

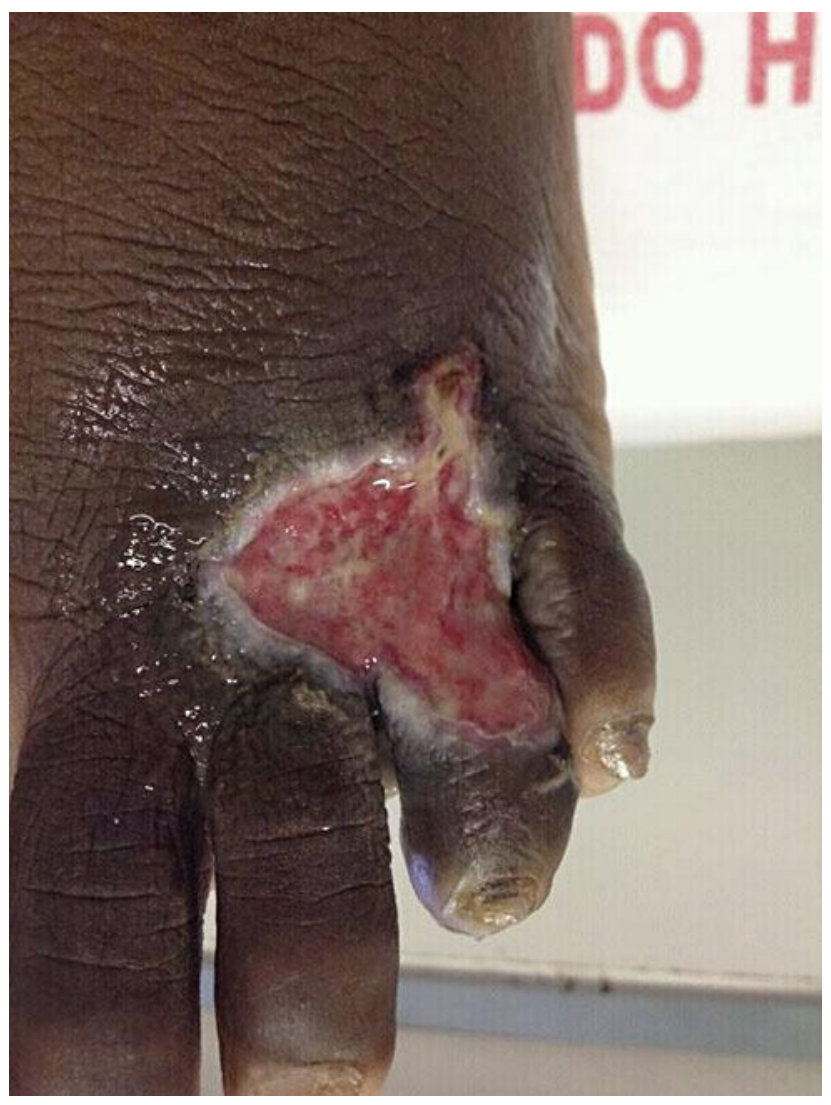

Fig. 4. After surgical debridement. 